\title{
High-risk human papilloma virus and cervical abnormalities in HIV-infected women with normal cervical cytology
}

Jonah Musa ${ }^{1,6^{*}}$, Chad Achenbach², Babafemi Taiwo², Baiba Berzins², Olugbenga Silas ${ }^{3}$, Patrick H Daru', Oche Agbaji $1^{4,6}$, Godwin Imade ${ }^{1,6}$, Atiene S Sagay ${ }^{1,6}$, John A Idoko ${ }^{4}$, Phyllis J Kanki ${ }^{5}$ and Robert L Murphy ${ }^{2}$

\begin{abstract}
Background: The prevalence of High-Risk Human papilloma virus (HR-HPV), a necessary cause of invasive cervical cancer (ICC) is relatively high in HIV infected women. Gaps exist in our knowledge of the optimal approaches for managing women who have HR-HPV with normal cervical cytology (NCC) particularly in settings of HIV infection.

Methods: Between May 2012 and June 2013 we conducted a colposcopic assessment of HIV-infected women with prior (NCC) and known HR-HPV status to compare cervical abnormalities in women with and without HR-HPV. Colposcopic examinations were done at the Operation Stop Cervical Cancer (OSCC) unit of the Jos University Teaching Hospital (JUTH), Jos, Nigeria. Abnormal colposcopic finding (ACF) was defined as areas of aceto-white epithelium involving the squamo-coulumnar junction, areas of punctation, mosaic pattern or atypical vessels. We compared proportions of ACF as well as histologic grades of cervical intra-epithelial neoplasia (CIN) in women with or without HR-HPV. Statistical analysis was done on STATA.

Results: We conducted colposcopic examinations in 78 out of $89(86.5 \%)$ eligible women. The mean age of the cohort was 32.4 years (SD \pm 4.6 ) with a median 32 years (IQR 29-36). After a mean follow up time of 20.1 months from the initial cervical pap cytology and HR-HPV testing, we found 12 of 78 (15.4\%) women with ACF. The odds for an ACF was statistically higher [OR $=4.0$ (95\% Cl: 1.1-14.7)] in women with HR-HPV compared to those without. Of the twelve women with ACF, subsequent histologic examination of colposcopically directed cervical biopsies confirmed CIN 1 in 4 cases (33.3\%), CIN 2 in 1 case (8.3\%), CIN 3 in 2 cases (16.7\%), carcinoma-in-situ (CIS) in 2 cases $(16.7 \%)$, and normal cervix in $3(25.0 \%)$. Overall, the proportion of women detected with any grade of CIN was $11.5 \%$ (9/78) and 6.4\% (5/78) were CIN 2 or greater lesion (CIN2+).

Conclusion: HIV-infected women with NCC and HR-HPV had a four-fold higher likelihood for an ACF. The practice of early colposcopic examination of HIV-infected women with prior NCC and HR-HPV may increase early detection of higher grade CIN and CIS cancer stages in our setting.
\end{abstract}

Keywords: HR-HPV, HIV, Cervical cytology, Cervical cancer, Nigeria

\footnotetext{
* Correspondence: drmusaj@yahoo.com

${ }^{1}$ Department of Obstetrics and Gynecology, University of Jos, Jos, Plateau

State, Nigeria

${ }^{6}$ AIDS Prevention Initiative in Nigeria, HIV program, Jos University Teaching

Hospital, Jos, Plateau State, Nigeria

Full list of author information is available at the end of the article
} 


\section{Introduction}

Cervical cancer was responsible for up to $25.4 \%$ of all new cancer cases in women in sub-Saharan Africa in 2012 [1]. Nigeria has a large burden of invasive cervical cancer and mortality [2] is equally high due to late presentation and limited treatment facilities. In Nigeria, 11,431 cases of cervical cancer and 5,952 cervical cancer deaths were reported in 2010 compare to 5,714 cases and 3,158 cervical cancer deaths in 1980 in the same country [2]. The high burden of human immuno deficiency virus (HIV) among women in Nigeria contributes to the growing incidence of premalignant lesions of the cervix as well as progression to invasive cervical cancer, necessitating the integration of cervical screening efforts using visual inspection with acetic acid (VIA) into existing HIV prevention, care and treatment programs in Nigeria [3].

In developed countries of the world, well-organized cervical cancer screening programs using Pap smear cytology has led to significant declines in invasive cervical cancer. Such national programs do not exist in most developing countries like Nigeria. Studies have shown that women with HIV have an increase risk of having high grade squamous intraepithelial lesions (SILs) with higher rates of progression to invasive stages $[4,5]$. Studies on the association of SILs and degree of HIV immunosupression have documented a significant risk in some and not others $[3,6,7]$. The role of high-risk human papilloma virus (HR-HPV) in cervical carcinogenesis has been well established from epidemiologic studies [8]. Studies have demonstrated the effectiveness of HR-HPV DNA testing in detecting high-grade squamous intraepithelial lesions and prevention of invasive cervical cancer cases compare to cervical cytology [9-12]. Also, the utility of HR-HPV DNA testing as a cervical cancer prevention strategy has demonstrated significant reduction in cervical cancer mortality compare to conventional Pap cytology in resource limited countries [13].

Additionally, studies have shown that even in settings where cervical cancer screening is available, conventional Pap cytology is associated with high false negative and positive results [14] and some high-grade cervical lesions have been missed in women with normal cervical cytology reports. The Athena trial [15] and a prevalence study in India have shown the potential benefits of HR-HPV testing, for the detection of high-grade cervical lesions among women with either atypical squamous intraepithelial lesions of undetermined significance or a negative pap smear cytology [16].

Gaps exist in the knowledge of optimal management approaches for women with normal pap cervical cytology and a positive HR-HPV particularly in the setting of HIV infection. To assess the possible role of HR-HPV DNA testing in detecting underlying high-grade cervical lesions in women with prior NCC in the setting of HIV infection, we conducted a pilot study of HR-HPV DNA testing in women with NCC in a cohort of HIV infected women in Jos, Nigeria. The prevalence and epidemiologic factors associated with HR-HPV in our patient population have been previously reported [17]. The current report focused on colposcopic examination findings and cervical abnormalities in women with or without HR-HPV in our cohort.

\section{Methods}

\section{Study setting, study population and procedures}

Between May 2012 and June 2013, we enrolled a cohort of HIV-infected women with NCC at the Reproductive Health Unit (RHU) of APIN of the APIN/Harvard PEPFAR HIV Clinic, Jos University Teaching Hospital, (JUTH) Jos, Nigeria. The RHU was set up in 2008 and is staffed by two reproductive health nurses and a gynecologist to address issues related to contraception and cervical cancer screening.

Routine care at JUTH includes CD4+ T cell (Partec, Gemany) and viral load (Roche Amplicor 1.5, lower detection limit 400 copies/ml) measurement before antiretroviral therapy (ART), then approximately every 3 months during ART. Initiation of ART follows the Nigerian National Guidelines for HIV and AIDS treatment and care in adolescents and adults, 2007 [18]. Other information routinely collected in the clinical care of patients at JUTH included the following: demographics, ART history and co-infections (hepatitis B, hepatitis $\mathrm{C}$ and tuberculosis). At enrollment, each patient gave written informed consent for collection and use of their medical information for research purposes.

A detailed questionnaire was administered to each participant to determine age, age at first coitus, parity, duration of HIV infection, ART history, previous abortions, history of contraception, previous Pap smear, smoking and alcohol consumption. Patient information not recalled by study participants such as duration of HIV disease, ART history etc. were extracted from their electronic database.

During the first part of this study, this cohort of women had cervical samples obtained for HR-HPV diagnosis by Hybrid Capture 2 (HC2) signal amplification (Digene Corporation, Gaithersburg, USA. The HC2 test is qualitative and a positive test indicates presence of one or more of the following 13 sub-types of HR-HPV: $16,18,31,33,35,39,45,51,52,56,58,59$ or 68 . Other details of the enrollment setting and sampling procedures for Pap smear preparation and interpretation has been described in the preliminary published work by Musa et al. [17]. At the time of enrollment, informed consent was obtained for a follow up visit during which a colposcopic examination would be done to detect any abnormality in the cervix. 
The colposcopic examinations were performed at the Operation Stop Cervical Cancer (OSCC) unit of the department of Obstetrics and Gynecology, JUTH. The study participants were contacted through phone calls by the study nurse and a study examination visit was scheduled. In situations where the participants were not successfully contacted through phone calls ("wrong numbers", "number not available", etc.), the researchers made efforts to track participants at their pharmacy drug pick-up visits where they received their regular antiretroviral drugs at the Adult HIV Treatment Clinic of JUTH. The colposcopic examinations were performed by a consultant gynecologist trained in VIA and colposcopic examination of the cervix. The gynecologist conducting the colposcopic examination was blinded to the HR-HPV status of the participant. Women who had detectable abnormalities were treated according to standard guidelines in our hospital. Abnormal colposcopic finding was defined as areas of aceto-white epithelium involving the squamo-coulumnar junction, areas of punctation, mosaic pattern or atypical vessels. Unsatisfactory colposcopic examination defined situations where the squamo-columnar junction was not clearly visualized. A tissue biopsy forceps was used to obtain cervical tissue as directed by the abnormal colposcopic area. Participants with normal colposcopic findings were reassured and booked for annual cervical pap cytology. The biopsy specimens were immediately fixed in formalin and transported to the histopathology laboratory for processing and histologic examination and interpretation by a trained pathologist who was blinded to the HR-HPV status of the specimen. The colposcopic findings were illustrated in a diagram and coded for subsequent entry into the study database.

\section{Procedure for colposcopic examination and histopathology reporting}

We used the Leisegang D-10625, Model1DS Ur Nr 55764, Colposcope, Berlin, Germany to examine the cervix. Each participant was placed in lithotomy position and an appropriate size Coscus speculum was introduced into the vagina to expose the cervix for examination. For each participant we first examined the vulva, vagina and the cervix before the application of $3 \%$ acetic acid solution. Prior to application of $3 \%$ acetic acid, the cervices seen to have excess cervical mucus were washed with $0.9 \%$ Normal saline to dislodge excess mucus discharge. Colposcopic abnormalities were described as normal, abnormal or unsatisfactory. Abnormal areas were biopsied using a punch cervical biopsy tissue forceps. The cervical tissues were processed in the histopathology laboratory. The Histopathologist was blinded to the HPV status of the participant and interpreted processed cervical samples either as Normal or CIN 1, CIN 2, CIN 3 or Carcinoma in
Situ (CIS) with either well-differentiated, moderate differentiated or poorly differentiated squamous cell carcinoma or other variants if applicable.

\section{Data collection and statistical analysis}

We created a study database that included routinely collected demographic parameters, CD4+ cell count (Partec, Munster, Germany), plasma HIV RNA (viral load; Roche COBAS Amplicor HIV-1 monitor test, version 1.5; Roche Diagnostics, GmbH, Mannheim Germany), HC2 HR-HPV status, date of colposcopic examinations, colposcopic findings and histology results (for those with colposcopic cervical tissue biopsy). To conduct statistical analyses, the database variables were coded for relevant statistical analysis on STATA. All analyses were performed using STATA version 11.0, College station, Texas, USA.

Summary statistics were generated using two-way tables of association to compare baseline socio-demographic characteristics of study participants with normal versus abnormal colposcopic examination findings. The Pearson's chi square and/or Fisher's exact test was performed where applicable. We also created relevant indicator variables in order to run univariabe logistic regression analyses to determine odds ratio of having colposcopic abnormalities. In the multivariable logistic regression model the association between positive HR-HPV and abnormal colposcopic findings was adjusted for age category $\geq 30$ years. Because of the relatively small numbers of participants in this pilot data, we estimated the proportions of histologic findings of the cervical biopsies in the study sample. All statistical tests were reported with corresponding 95\% confidence interval and p-values. Probability estimates $<0.05$ were considered statistically significant.

\section{Human subject protection}

Institutional Review Board approval was obtained from the Harvard School of Public Health for identification and enrollment of HIV-infected women into care, treatment and other support services at APIN, JUTH. Secondary use of data approval was also granted by the Harvard School of Public Health to use CD4+ T cell count, viral load and other relevant patient data. The protocol for this study was approved by the JUTH Human Subject Ethics Committee.

\section{Results}

We studied 78 women out of 89 eligible participants (86.5\%) who completed colposcopic examination (Table 1). Of the 78 HIV-infected women included in this study, 30 (38.5\%) were HR-HPV positive and 48 (61.5\%) were HR-HPV negative.

Socio-demographic characteristics of the study cohort have been summarized in Table 1. The mean age was 
Table 1 Socio-demographic characteristics of HIV infected women with normal cervical cytology who had colposcopic follow up examination in Jos Nigeria

\begin{tabular}{|c|c|c|c|}
\hline \multicolumn{4}{|l|}{$\mathrm{N}=78$} \\
\hline Variable & $\begin{array}{l}\text { Abnormal } \\
\text { findings }\end{array}$ & $\begin{array}{l}\text { Normal } \\
\text { finding }\end{array}$ & p-value \\
\hline Age (years) & $34.7 \pm 5.5$ & $32.9 \pm 4.4$ & 0.069 (t-test) \\
\hline \multicolumn{4}{|l|}{ Parity $(N=78)$} \\
\hline 0 & $2(18.2)$ & $9(81.8)$ & 0.578 (Fisher) \\
\hline$\geq 1$ & 10(14.9) & $57(85.1)$ & \\
\hline \multicolumn{4}{|l|}{$\begin{array}{l}\text { HR_HPV status } \\
(\mathrm{N}=78)\end{array}$} \\
\hline Positive & $8(26.7)$ & $22(73.3)$ & 0.05 (Fisher) \\
\hline Negative & $4(8.3)$ & $44(91.7)$ & \\
\hline \multicolumn{4}{|c|}{$\begin{array}{l}\text { History of previous } \\
\text { abortions }(N=76)\end{array}$} \\
\hline Yes & $6(18.2)$ & $27(81.8)$ & 0.616 (Pearson) \\
\hline No & $6(14.0)$ & $37(86.0)$ & \\
\hline \multicolumn{4}{|c|}{$\begin{array}{l}\text { History of contraceptive } \\
\text { use }(N=78)\end{array}$} \\
\hline Never & $4(21.1)$ & $15(78.9)$ & 0.224 (Fisher) \\
\hline Past & $5(20.8)$ & 1979.2) & \\
\hline Current & $3(8.6)$ & $32(91.4)$ & \\
\hline \multicolumn{4}{|l|}{$\begin{array}{l}\text { Age_Category } \\
(\mathrm{N}=78)\end{array}$} \\
\hline$\leq 30$ & $2(7.1)$ & 26(92.9) & 0.122 (Fisher) \\
\hline$>30$ & 10(20.0) & $40(80.0)$ & \\
\hline \multicolumn{4}{|l|}{$\begin{array}{l}\text { CD4+ cell count } \\
\text { category }(N=78)\end{array}$} \\
\hline$<350 / \mathrm{mm}^{3}$ & $4(25.0)$ & $12(75.0)$ & 0.449 (Fisher) \\
\hline$\geq 350 / \mathrm{mm}^{3}$ & $9(14.5)$ & $53(85.5)$ & \\
\hline \multicolumn{4}{|c|}{$\begin{array}{l}\text { Viral load category } \\
(N=78)\end{array}$} \\
\hline$<400$ copies/ml & 11(19.0) & $47(81.0)$ & 0.498 (Fisher) \\
\hline$\geq 400$ copies $/ \mathrm{ml}$ & $2(10.0)$ & $18(90.0)$ & \\
\hline
\end{tabular}

32.4 years ( $\mathrm{SD} \pm 4.6$ years) and median age 32 years (IQR 29-36 years).

\section{Colposcopic abnormalities and HR-HPV}

Colposcopic examinations were performed after a mean of 20.1 months from the initial cervical pap cytology and HR-HPV status evaluation. The mean follow up time between initial Pap cytology and subsequent colposcopic evaluation was comparable for women who were positive HR-HPV (20.5 months) and those negative HR-HPV (19.9 months); p-value 0.554. Colposcopy revealed 12 of $78(15.4 \%)$ women with abnormal findings. The odds ratio (OR) of having an abnormal colposcopic examination finding was 4.0 (95\% CI: 1.1-14.7) in women who were HR-HPV positive compared to HR-HPV negative; p-value 0.039 (Table 1 and Figure 1).

\section{Colposcopic abnormalities and histologic diagnoses of CIN/Cancer}

Of the twelve women with abnormal colposcopic findings, subsequent histologic examination confirmed CIN 1 in 4 cases (33.3\%), CIN 2 in 1 case (8.3\%), CIN 3 in 2 cases (16.7\%), carcinoma-in-situ (CIS) in 2 cases (16.7\%), and normal cervix in 3 cases (25.0\%) (Table 2). In all, 5 out $12(41.7 \%)$ of those with abnormal colposcopic findings had a confirmed CIN 2 or greater lesion $(\mathrm{CIN} 2+)$ of the cervix. Overall, the proportion of women detected with any grade of CIN was $11.5 \%$ (9/78) and CIN2+ was $6.4 \%$ (5/78) in our cohort. Subsequent analysis of CIN $2+$ lesions detected by HR-HPV status showed that $13.3 \%(4 / 30)$ were detected in the HR-HPV positive group compare to $2.1 \%(1 / 48)$ in the HR-HPV negative group (P-value 0.0494).

Colposcopic abnormalities, age category and HR-HPV status In a multivariabe logistic regression model including age $\geq 30$ years and HR-HPV positive, we found an OR $=4.9$ (95\% CI: 0.91-26.2, p value 0.065) for age $\geq 30$ years and an $\mathrm{OR}=5.4$ (95\% CI: 1.4-21.5, p value 0.016) for an HR-HPV positive woman of having an abnormal colposcopic examination finding (Table 3).

\section{Discussion}

In this pilot study, after a mean follow up time of 20.1 months, we documented abnormal colposcopic findings in 12 of 78 (15.4\%) HIV-infected women with prior NCC. Women with HR-HPV had a five-fold higher likelihood of an abnormal colposcopic description compare to those without after controlling for age. We also observed that women with positive HR-HPV had a higher proportion of CIN 2+ cervical abnormalities compare to women negative for HR-HPV. Overall, the proportion of any CIN lesion was $11.5 \%$ (9/78) and CIN2+ was 6.4\% (5/78) in our cohort.

In a cohort study reported from India [16], the authors described a prevalence of $10.0 \%$ of HR-HPV types 16 and 18 in women with cytologically negative Pap smear and any CIN lesion was found in 15\% (19 out of 123 women with negative pap cytology) following colposcopy and directed biopsies. A meta-analysis of over 20 studies showed a high prevalence of $36.3 \%$ of any HR-HPV among HIV infected women with normal cervical cytology [19] and HIV infected women with high-grades lesions were significantly more likely to be infected with HPV types $11,18,33,51,52,53,58$ and 61 . Although, the method of HR-HPV detection in our cohort was based on HC2 which shows positivity for any of the following HR-HPV types $(16,18,31,33,35,39,45,51,52,56,58$, 


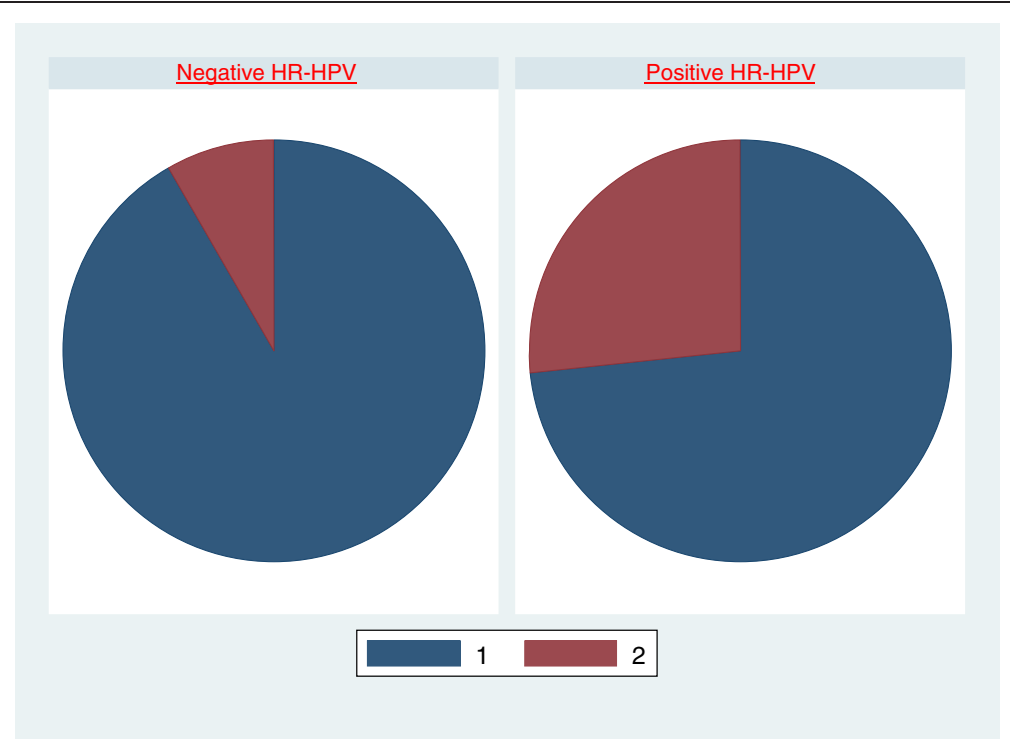

Figure 1 Normal colposcopic (1) and abnormal colposcopic (2) examinations in HIV infected women with positive HR-HPV compare to those negative for HR-HPV.

59 or 68), the proportion of any CIN lesion detected in our pilot data is comparable with the findings described in India [16]. The India study used specific PCR primers to detect the most common HR-HPV types 16 and 18, which have been reported to account for $70 \%$ of cervical cancer globally [8]. Other studies have found a similarly high association of HIV and HR-HPV infection, but reported a higher prevalence and association of higher grade squamous lesions with PCR HR-HPV sub-types

Table 2 Summary of main outcome for HIV infected women with prior normal cervical cytology with positive HR-HPV or negative HR-HPV in Jos Nigeria

\begin{tabular}{llll}
\hline Outcome & $\begin{array}{l}\text { Positive } \\
\text { HR-HPV }\end{array}$ & $\begin{array}{l}\text { Negative } \\
\text { HR-HPV }\end{array}$ & P-value \\
\hline $\begin{array}{l}\text { Mean follow up time (Months) } \\
\text { Colposcopic finding }\end{array}$ & $20.5 \pm 4.1$ & $19.9 \pm 4.3$ & $0.554^{*}$ \\
Abnormal & $9(29.0)$ & $22(71.0)$ & $0.001^{\dagger}$ \\
Normal & $3(6.4)$ & $44(93.6)$ & \\
Cervical biopsy taken & & & \\
Yes & $10(83.3)$ & $2(16.7)$ & $0.001^{\dagger}$ \\
No & $21(32.8)$ & $43(67.2)$ & \\
Histologic diagnosis & & & \\
Normal cervix & $1(33.3)$ & $2(66.7)$ & \\
CIN I & $3(75.0)$ & $1(25.0)$ & \\
CIN II & $0(0.0)$ & $1(100.0)$ & \\
CIN III & $2(100.0)$ & $0(0.0)$ & \\
Cervical Carcinoma in situ (CIS) & $2(100.0)$ & $0(0.0)$ & \\
Proportion of CIN 2+ detected & 0.133 & 0.021 & $0.0494^{\ddagger}$ \\
\hline
\end{tabular}

*Student t-test for means, ${ }^{\dagger}$ Fisher's exact $\mathrm{p}$-values, ${ }^{*} \mathrm{t}$-test of proportion.
52 and 58 [20]. A recent study on the burden and distribution of HR-HPV types among HIV-infected women in Western Nigeria found a comparably higher prevalence of HR-HPV among HIV-infected women than negative controls with types $16,35,58$ and 31 being the most prevalent types [21]. Additionally, the ATHENA trial [15], where over 1,500 women with atypical squamous cells of undetermined significance (ASCUS) were examined colposcopically and their specific HR-HPV determined by Cobas 4800 , found higher absolute risk of detection of CIN 2+ in women with HR-HPV 16/18 compared to the detection of pooled HR-HPV positive or HR-HPV negative women $(24.4 \%, 14.0 \%$ and $0.8 \%$ respectively). These findings suggest that HR-HPV testing could increase the detection rate of SILs/Cervical cancer if colposcopic examinations are performed on patients with

Table 3 Univariate and multivariate logistic regression of abnormal colposcopic examination findings in HIV infected women with normal cervical cytology in Jos Nigeria

\begin{tabular}{llll}
\hline Variable & Odds ratio (OR) & $\mathbf{9 5 \% ~ C l}$ & P-Value \\
\hline CD4 <350 cells $/ \mathrm{mm}^{3}$ & 1.03 & $0.30-3.48$ & 0.968 \\
Positive HR-HPV (HC2) & 4.00 & $1.08-14.75$ & 0.037 \\
Previous abortions & 0.73 & $0.21-2.51$ & 0.617 \\
Age $\geq 30$ years & 3.58 & $0.73-17.45$ & 0.115 \\
Viral load >400 RNA copies/ml & 0.45 & $0.10-2.22$ & 0.33 \\
Positive HR-HPV (HC2) & 5.44 (AOR) & $1.37-21.50$ & 0.016 \\
Age $\geq 30$ years & 4.87 (AOR) & $0.91-26.17$ & 0.065 \\
\hline
\end{tabular}

$\mathrm{AOR}=$ Adjusted Odds Ratio of having an abnormal colposcopic examination findings in a model of positive HR-HPV and Age $\geq 30$ years as co-variates (Hosmer-Lemeshow goodness-of-fit p-value 0.782). 
the most prevalent sub-types causing cancer in a particular setting.

Our pilot data showed that women who had a positive HR-HPV had a five-fold higher likelihood of an abnormal colposcopic examination after adjusting for age. Other factors such as CD4+ T cell count, HIV-1 viral load, previous abortions, and use of contraceptives were not significantly associated with having an abnormal colposcopic examination finding. A prior study in Jos during an era when accessibility and use of antiretroviral drugs was limited [6], found a high prevalence of cervical dysplasia among HIV-infected women whose CD4+ T cell count was less than $200 \mathrm{cell} / \mathrm{mm}^{3}$, high viral load $(101,781$ copies $/ \mathrm{ml})$ and those with a clinical evidence of HPV infection on visual inspection. A study from a Brazilian HIV-infected cohort, found a higher association of current cigarette smoking, CD4+ T cell count less than 350 cells $/ \mathrm{mm}^{3}$, and HR-HPV with colposcopic/histopathologic diagnosis of CIN2+ lesions [22]. Studies have shown a significant association of cervical cancer risk with cigarette smoking, oral contraceptive use, multiparity, impaired cellular immunity and chronic inflammation [23]. Our small study population undergoing successful antiretroviral therapy, may further explain the lack of difference in colposcopic abnormalities with CD4+ T cell count, viral load and other socio-demographic characteristics.

Subsequent colposcopically directed biopsy and histologic diagnosis a significant difference in the proportion of CIN 2+ lesions detected in HIV infected women who were HR-HPV positive compare to those HR-HPV negative. These findings have implications in the practice of cervical cancer screening in our setting. First, since colposcopy and directed biopsy with histologic examination is the gold-standard for the diagnosis of CIN/or invasive cancer; women with HR-HPV are more likely to have such colposcopic examination and directed biopsies thereby increasing the chances of diagnosing high-grade lesions and/or cancer. Results of HPV genotype distribution from meta- analysis data have shown that the HPV genotype distribution in low grades cervical lesions differs from that in cervical cancer [24], suggesting the need to conduct studies on the type-specific HPV genotypes causing cervical cancer in different geographic settings. Several previous studies on the role of colposcopiy in diagnosing squamous intraepithelial lesions and cervical cancer have reported a higher risk of detecting SILs/cancer in women who had prior HR-HPV during follow up compared to HR-HPV negative controls [22,25,26].

One alarming finding in our pilot study is the detection of 2 cases of CIS of the cervix following colposcopic examination and directed biopsies in women with prior NCC after only about 20 months of follow up. Indeed, studies have shown an increased hazard of rapid progression from CIN to ICC stages in women infected with
HIV compared to HIV-uninfected controls [5]. This finding suggests that women infected with HIV in our setting may benefit from early colposcopic examination of the cervix even when Pap smear cytology is normal.

The major strength of this study lies in the fact that HR-HPV testing is not yet part of our screening for cervical cancer in Nigeria and this is first study examining its possible role in detecting high-grade cervical lesions particularly in HIV-infected women with NCC. We were also able to enroll $86 \%$ of the initial cohort and conducted colposcopic examinations irrespective of HR-HPV status. We must however, acknowledge the limitations of a relatively small sample size, which may have reduced the statistical power to control for potential confounding effects on detection of CIN2+ in our cohort. We also did not perform colposcopic examination at the time of initial Pap or HR-HPV determination and the abnormalities/CIN lesions detected at follow up colposcopy examinations may have existed at the time of initial Pap cytology examination.

In all we detected $6.4 \%(5 / 78)$ CIN2 or greater in this small pilot cohort out of which 2 cases were CIS. Since HIV-infected women have a significant hazard of progression from CIN to ICC [5], our data suggests that in situations where facilities for colposcopic examination are limited, efforts should be focused on conducting early colposcopic examination of HIV-infected women with NCC who are over 30 years and positive HR-HPV. We need to study a larger cohort with a longer follow up time, across different regions in Nigeria including HIV positive and negative women to have better insights on the optimal approach for managing HIV infected women with NCC in our setting.

\section{Competing interests}

The authors declare that they have no competing interests.

\section{Authors' contributions}

JM conceptualized, designed, supervised data collection, conducted statistical analysis, drafted the initial manuscript and approved the final version for publication. CA, BT, BB, and RLM contributed in conceptualization and design of the study, interpretation of results, manuscript writing and approval of the final version. ASS, GI, JAI, OA, OS, PHD and PJK contributed in modifying the study design, data collection, analysis and editing of the manuscript. All the authors read and approved the final version of the manuscript.

\section{Acknowledgement}

This study was funded through a seed award on completion of a Master of Science in Clinical Investigation training at Northwestern University, Chicago supported by the Northwestern University AIDS International Training and Research Program (NU-AITRP), Award Number- D43TW007995 and the Jos-Northwestern HIV Malignancy grant (\# D43TW009575) from the Fogarty International Center/National Institutes of Health. This work was funded in part by the U.S. Department of Health and Human Services, Health Resources and Services Administration [U51HA02522-01-01]. We also acknowledge the Medical Education Partnership Initiative in Nigeria (MEPIN) project funded by Fogarty International Center (R24TWDD8878). The contents are solely the responsibility of the authors and do not represent the official views of the funding institutions. 


\section{Author details}

${ }^{1}$ Department of Obstetrics and Gynecology, University of Jos, Jos, Plateau State, Nigeria. ${ }^{2}$ Center for Global Health, Northwestern University, Chicago, IL, USA. ${ }^{3}$ Department of Pathology, University of Jos, Jos, Plateau State, Nigeria. ${ }^{4}$ Department of Medicine, University of Jos, Jos, Plateau State, Nigeria. ${ }^{5}$ Department of Immunology and Infectious Diseases, Harvard School of Public Health, Boston, MA, USA. ${ }^{6}$ AIDS Prevention Initiative in Nigeria, HIV program, Jos University Teaching Hospital, Jos, Plateau State, Nigeria.

Received: 1 July 2014 Accepted: 7 October 2014

Published: 3 November 2014

\section{References}

1. Parkin DM, Bray F, Ferlay J, Jemal A: Cancer in Africa 2012. Cancer Epidemiol Biomarkers Prev [Internet] 2014. Available from: http://www.ncbi.nIm.nih.gov/ pubmed/24700176.

2. Forouzanfar MH, Foreman KJ, Delossantos AM, Lozano R, Lopez AD, Murray CJL, Nahavi M: Breast and cervical cancer in 187 countries between 1980 and 2010: a systematic analysis. Lancet [Internet] 2011, 378(9801):1461-1484. Available from: http://www.ncbi.nlm.nih.gov/pubmed/ 21924486

3. Odafe S, Torpey K, Khamofu H, Oladele E, Adedokun O, Chabikuli O, Mukaddas H, Usman Y, Aiyenigba B, Okoye M: Integrating cervical cancer screening with HIV care in a district hospital in Abuja, Nigeria. Niger Med J [Internet] 2013, 54(3):176-184. Available from: http://www.pubmedcentral. nih.gov/articlerender.fcgi?artid=3719244\&tool=pmcentrez\&rendertype= abstract.

4. Anderson JR, Paramsothy $P$, Heilig C, Jamieson DJ, Shah K, Duerr A: Accuracy of Papanicolaou test among HIV-infected women. Clin Infect Dis [Internet] 2006, 42(4):562-568. Available from: http://www.ncbi.nlm.nih.gov/ pubmed/16421802.

5. Denslow SA, Rositch AF, Firnhaber C, Ting J, Smith J: Incidence and progression of cervical lesions in women with HIV: a systematic global review. Int J STD AIDS 2014, 25(3):163-177.

6. Agaba PA, Thacher TD, Ekwempu CC, Idoko JA: Cervical dysplasia in Nigerian women infected with HIV. Int J Gynaecol Obstet [Internet] 2009, 107(2):99-102. Available from: http://www.ncbi.n/m.nih.gov/pubmed/19619874.

7. Ezechi OC, Pettersson KO, Okolo CA, Ujah IAO, Ostergren PO: The Association between HIV infection, antiretroviral therapy and cervical squamous intraepithelial lesions in South Western Nigerian women. PLoS One [Internet] 2014, 9(5):e97150. Available from: http://www.pubmed central.nih.gov/articlerender.fcgi?artid=4014606\&tool=pmcentrez\& rendertype $=$ abstract

8. Castellsagué X: Natural history and epidemiology of HPV infection and cervical cancer. Gynecol Oncol [Internet] 2008, 110(3 Suppl 2):S4-S7. Available from: http://www.ncbi.nlm.nih.gov/pubmed/18760711

9. Bulkmans NWJ, Berkhof J, Rozendaal L, Kemenade FJ V, Boeke AJP, Bulk S, Voorhorst FJ, Verheijen RHM, Groningen K van, Boon ME, Ruitinga W, Ballegooigen M van, Snijders PJF, Meijer CJLM: Human papillomavirus DNA testing for the detection of cervical intraepithelial neoplasia grade 3 and cancer : 5-year follow-up of a randomised controlled implementation trial. Lancet 2007, 370:1764-1772.

10. Ronco G, Giorgi-rossi P, Carozzi F, Confortini M, Palma PD, Del MA, Ghiringhello B, Girlando S, Gillio-Tos A, De Marco L, Naldoni C, Pierotti P, Rizzolo R, Schincaglia P, Zorzi M, Zappa M, Segnan N, Cuzick J, and the New Technologies for Cervical Cancer Screening (NTCC) Working Group: Efficacy of human papillomavirus testing for the detection of invasive cervical cancers and cervical intraepithelial neoplasia: a randomised controlled trial. Lancet Oncol 2010, 11:249-257.

11. Ronco G, Dillner J, Elfström KM, Tunesi S, Snijders PJF, Arbyn M, Kitchener H, Segnan N, Gilham C, Giorgi-Rossi P, Berkhof J, Peto J, Meijer CJLM, and the International HPV screening working group: Efficacy of HPV-based screening for prevention of invasive cervical cancer: follow-up of four European randomised controlled trials. Lancet 2014, 383:524-532.

12. Rijkaart DC, Berkhof J, Rozendaal L, van Kemenade FJ, Bulkmans NWJ, Heideman DM, Kenter GG, Cuzick J, Snijders PJF, Meijer CJLM: Human papillomavirus testing for the detection of high-grade cervical intraepithelial neoplasia and cancer: final results of the POBASCAM randomised controlled trial. Lancet Oncol [Internet] 2012, 13(1):78-88. Available from: http://www.ncbi.nlm.nih.gov/pubmed/22177579.
13. Sankaranarayanan $R$, Nene BM, Shastri SS, Jayant $K$, Muwonge $R$, Budurkh AM, Hingmire S, Malvi SG, Thorat R, Kothari A, Chinoy R, Kelkar R, Kane S, Desai S, Keskar VR, Rajeshwarkar R, Panse N, Dinshaw KA: HPV screening for cervical cancer in rural India. N Engl J Med 2009, 360(14):1385-1394.

14. Sankaranarayanan R, Gaffikin L, Jacob M, Sellors J, Robles S: A critical assessment of screening methods for cervical neoplasia. Int J Gynaecol Obstet [Internet] 2005, 89(Suppl 2):S4-S12. Available from: http://www.ncbi. nlm.nih.gov/pubmed/15823266.

15. Stoler MH, Wright TC, Sharma A, Apple R, Gutekunst K, Wright TL: High-risk human papillomavirus testing in women with ASC-US cytology: results from the ATHENA HPV study. Am J Clin Pathol [Internet] 2011, 135(3):468-475. Available from: http://www.ncbi.nlm.nih.gov/pubmed/21350104

16. Arora R, Kumar A, Prusty BK, Kailash U, Batra S, Das BC: Prevalence of high-risk human papillomavirus (HR-HPV) types 16 and 18 in healthy women with cytologically negative Pap smear. Eur J Obstet Gynecol Reprod Biol [Internet] 2005, 121(1):104-109. Available from: http://www.ncbi. nlm.nih.gov/pubmed/15950365.

17. Musa J, Taiwo B, Achenbach C, Olugbenga S, Berzins B, Sagay AS, Idoko JA, Kanki PJ, Murphy RL: High-risk human papillomavirus among HIV-infected women with normal cervical cytology: a pilot study in Jos, Nigeria. Arch Gynecol Obstet [Internet] 2013, 288(6):1365-1370. Available from: http://www.ncbi.nlm.nih.gov/pubmed/23700253.

18. Federal Ministry of Health Nigeria: Criteria for Initiation of Antiretrovira Therapy. In National Guidelines for HIV and AIDS Treatmment and Care in Adolescents and Adults. Abuja, Nigeria: FMOH, Nigeria; 2007. p. Section 5: 5-35.

19. Clifford GM, Gonçalves MAG, Franceschi S: Human papillomavirus types among women infected with HIV: a meta-analysis. AIDS [Internet] 2006 20(18):2337-2344. Available from: http://www.ncbi.nlm.nih.gov/pubmed/ 17117020

20. Luque AE, Jabeen M, Messing S, Lane C, Demeter LM, Rose RC, Reichman RC: Prevalence of human papillomavirus genotypes and related abnormalities of cervical cytological results among HIV-1-infected women in Rochester, New York. J Infect Dis [Internet] 2006, 194(4):428-434. Available from: http://www.ncbi.nlm.nih.gov/pubmed/16845625.

21. Ezechi OC, Ostergren PO, Nwaokorie FO, Ujah IAO, Odberg Pettersson K: The burden, distribution and risk factors for cervical oncogenic human papilloma virus infection in HIV positive Nigerian women. Virol J [Internet] 2014, 11:5. Available from: http://www.pubmedcentral.nih.gov/articlerender. fcgi?artid $=3896716 \&$ tool=pmcentrez\&rendertype $=$ abstract .

22. De Andrade ACV, Luz PM, Velasque L, Veloso VG, Moreira RI, Russomano F, Chicarino-Coelho J, Pires E, Levi JE, Grinsztejn B, Friedman RK: Factors associated with colposcopy-histopathology confirmed cervical intraepithelial neoplasia among HIV-infected women from Rio De Janeiro, Brazil. PLoS One [Internet] 2011, 6(3):e18297. Available from: http://www.pubmedcentral. nih.gov/articlerender.fcgi?artid=3068170\&tool=pmcentrez\&rendertype $=$ abstract.

23. Schiffman M, Wentzensen N, Wacholder S, Kinney W, Gage JC, Castle PE: Human papillomavirus testing in the prevention of cervical cancer. J Natl Cancer Inst [Internet] 2011, 103(5):368-383. Available from: http://www.pubmedcentral.nih.gov/articlerender.fcgi?artid=3046952\& tool=pmcentrez\&rendertype=abstract

24. Clifford GM, Rana RK, Franceschi S, Smith JS, Gough G, Pimenta JM: Human papillomavirus genotype distribution in low-grade cervical lesions: comparison by geographic region and with cervical cancer. Cancer Epidemiol Biomarkers Prev [Internet] 2005, 14(5):1157-1164. Available from: http://www.ncbi.nlm.nih.gov/pubmed/15894666.

25. Liaw KL, Glass a G, Manos MM, Greer CE, Scott DR, Sherman M, Burk RD, Kurman RJ, Wacholder S, Rush BB, Cadell DM, Lawler P, Tabor D, Schiffman $M$ : Detection of human papillomavirus DNA in cytologically normal women and subsequent cervical squamous intraepithelial lesions. J Natl Cancer Inst [Internet] 1999, 91(11):954-960. Available from: http://www.ncbi. nlm.nih.gov/pubmed/10359548

26. You K, Liang X, Qin F, Guo Y, Geng L: High-risk human papillomavirus DNA testing and high-grade cervical intraepithelial lesions. Aust N Z J Obstet Gynaecol [Internet] 2007, 47(2):141-144. Available from: http://www. ncbi.nlm.nih.gov/pubmed/17355305.

doi:10.1186/1750-9378-9-36

Cite this article as: Musa et al:: High-risk human papilloma virus and cervical abnormalities in HIV-infected women with normal cervical cytology. Infectious Agents and Cancer 2014 9:36. 